\title{
Highlights on selected microscopy techniques to study zebrafish developmental biology
}

\author{
Ahmed Abu-Siniyeh ${ }^{1 *}$ and Walid Al-Zyoud ${ }^{2}$
}

\begin{abstract}
Bio-imaging is a tedious task when it concerns exploring cell functions, developmental mechanisms, and other vital processes in vivo. Single-cell resolution is challenging due to different issues such as sample size, the scattering of intact and opaque tissue, pigmentation in untreated animals, the movement of living organs, and maintaining the sample under physiological conditions. These factors might lead researchers to implement microscopy techniques with a suitable animal model to mimic the nature of the living cells.

Zebrafish acquired its prestigious reputation in the biomedical research field due to its transparency under advanced microscopes. Therefore, various microscopy techniques, including Multi-Photon, Light-Sheet Microscopy, and Second Harmonic Generation, simplify the discovery of different types of internal functions in zebrafish. In this review, we briefly discuss three recent microscopy techniques that are being utilized because they are non-invasive in investigating developmental events in zebrafish embryo and larvae.
\end{abstract}

Keywords: Zebrafish, Development, Animal model, Two-Photon Microscopy, Second Harmonic Generation, LightSheet Microscopy

\section{Introduction}

Imaging a live organism is not easily accessible because matching a suitable animal model with a proper microscopy technique is challenging. In this context, different advanced microscopy approaches on different animal models were used either to explore the etiology of diseases or to explore the feasibility of discovering new drugs. However, some of these techniques suffer severe limitations.

The most advantageous features of zebrafish are its transparency, its amenability to optical imaging, in addition to the ease of generation of transgenic lines. These features lead zebrafish to be an excellent animal model for addressing questions for in vivo studies in vertebrates. Different applications were implemented for

\footnotetext{
* Correspondence: akabusiniyeh@tu.edu.sa

${ }^{1}$ Clinical Laboratory Sciences Department, College of Applied Medical

Science, Taif University, Taif, Kingdom of Saudi Arabia

Full list of author information is available at the end of the article
}

this purpose, especially advanced microscopy techniques such as Fluorescence Correlation Spectroscopy (FCS), Multi-Photon Microscopy (MPM), and Light-Sheet Microscopy (LSM) [1-3]. Reaching capabilities in elucidating and understanding pathophysiological events is a substantial step to reveal the anatomical and pathophysiological changes in vivo.

Here, we briefly discuss the engagement of zebrafish in three models of advanced microscopy techniques: TwoPhoton Microscopy (TPM), Second Harmonic Generation, (SHG), and Light-Sheet Microscopy (LSM). Different reasons were behind selecting these techniques include non-invasiveness, the high resolution in imaging intact biological samples with deep penetration, and success in imaging live zebrafish embryos and larvae without affecting their viability or behavior.

(c) The Author(s). 2020 Open Access This article is licensed under a Creative Commons Attribution 4.0 International License, which permits use, sharing, adaptation, distribution and reproduction in any medium or format, as long as you give appropriate credit to the original author(s) and the source, provide a link to the Creative Commons licence, and indicate if changes were made. The images or other third party material in this article are included in the article's Creative Commons licence, unless indicated otherwise in a credit line to the material. If material is not included in the article's Creative Commons licence and your intended use is not permitted by statutory regulation or exceeds the permitted use, you will need to obtain permission directly from the copyright holder. To view a copy of this licence, visit http://creativecommons.org/licenses/by/4.0/ The Creative Commons Public Domain Dedication waiver (http://creativecommons.org/publicdomain/zero/1.0/) applies to the data made available in this article, unless otherwise stated in a credit line to the data. 


\section{Zebrafish and microscopy}

Transparency of zebrafish is a dominant feature; therefore, many recent studies implemented zebrafish with advanced microscopy to explore significant events related to vertebrate development, functional genomics, organ functions, behavior, toxicology, and drug discovery [4-6]. Live zebrafish embryos were employed in glycans imaging by treating zebrafish with an unnatural sugar to label their cell-surface glycans with azides metabolically. A significant increase in de novo glycan biosynthesis was recorded in different organs during development. The multicolor detection helped in conducting a spatiotemporal investigation of glycan trafficking and expression that cannot be achieved by conventional microscopy [7]. Apoptotic embryonic cells of zebrafish were visualized in vivo, and scientists performed successful labeling for apoptotic cells by genetically encoded fluorescent reporter protein. As an exceptional animal model, the authors described the patterns of apoptosis and the neuronal cell death at a single-cell resolution [8].

Later, apoptosis was investigated in live zebrafish larvae through implementing a combination of Fluorescence Lifetime Imaging (FLIM) with Optical Projection Tomography (OPT). In this work, the application of FLIM OPT was a pioneer in monitoring apoptosis over time in vivo with genetically expressed Förster Resonant Energy Transfer (FRET) biosensors [9].

Zhao and colleagues utilized probes in live zebrafish embryos with a high spatial resolution to verify a functional imaging method through multiple (FRET). They showed a possibility to measure the levels of $\mathrm{Ca}^{2+}$ and cAMP at low resolution by expressing dual FRET sensors. The FRET was rapid, robust, and compatible with a varied range of sensors for functional microscopy in vivo. Therefore, it was proposed that FRET would facilitate the imaging of complex cellular systems in whole live organisms [10]. A new ratiometric two-photon fluorescent probe (RN3) was recently synthesized to detect Palladium $2^{+}\left(\mathrm{Pd} 2^{+}\right)$in living zebrafish larvae by FRET, with a significant advantage in monitoring $\mathrm{Pd} 2^{+}$ due to that RN3 possessed excellent biocompatibility and low cell cytotoxicity [11].

\section{Zebrafish by Two-Photon Microscopy}

The new high-resolution and non-invasive imaging techniques on transparent zebrafish embryos enabled scientists to visualize morphogenetic activities during the early development of zebrafish and understand the cell membrane and its organization in a whole animal model $[1,12]$. Many fluorescent lipid analogs and probes have been effectively implemented in zebrafish [13-15]. For example, new nonlinear optical techniques, included label-free visualization of lipids, have released new opportunities using zebrafish in lipid studies [16]. The first membrane image of lipid order in a whole living organism was reported in 2010. Laurdan and Two-Photon Microscopy were used to take three-dimensional images of embryonic cell membranes in zebrafish, where a high lipid order in the apical surfaces of polarized epithelial cells was observed [12] (Fig. 1).

Calcium imaging in the zebrafish in vivo included a two-photon microscope, as reported by Renninger and Orger 2013. Genetically encoded calcium indicators have successfully unlocked the constrains in recording neural population activity in zebrafish. Two-photon Microscopy enabled imaging the whole brain with single-cell resolution, generating interesting brain-wide functional maps in zebrafish [17].

By using deep Two-Photon Microscopy in zebrafish, microdomains in polarized epithelial cells were visualized by Laurdan dye, where the membrane order was quantified in the gut, kidney, and liver ductal epithelia during different developmental stages, from 3 to $11 \mathrm{dpf}$ (days postfertilization). It was found that the membrane order of polarized epithelial cells of the three types of tissues mentioned above is significantly changing during development with high membrane orders acquired at $6 \mathrm{dpf}$ stage (Fig. 2). This observation emphasized the critical role of lipid rafts in cell functions and the organogenesis in zebrafish during early developmental stages [18].

\section{Drawbacks of Two-Photon Microscopy}

Despite many advantages of Two-Photon Microscopy, there are also some drawbacks to such a technique. For example, photobleaching and photodamage are the most common artifacts at the focal volume, where photochemical interactions occur. Due to the high light exposure on the sample, it may induce unfavorable heat; this may lead to direct damage and considerable morphological changes to the sample, especially in pigmented tissue [19]. But this kind of damage might be reduced by exposing the sample to shorter laser pulses [20]. Nonlinear damage may also occur by Two-Photon Microscopy, which are significant contributors to cell phototoxicity [21, 22]. Different approaches and modifications could be implemented to reduce phototoxicity and photodamage that might occur during live fluorescence microscopy, such as limiting sample illumination to a focal plane. Applying such a strategy allowing more consistent and reproducible image data acquisition in high resolution with wide-range periods of observation. In summary, limiting Two-Photon Microscopy drawbacks depends on well-controlled and well-designed experiments in terms of light exposure power and time [23].

\section{Zebrafish by Second Harmonic Generation}

A higher harmonic generation technique, which includes the Second and Third Harmonic Generation, is 


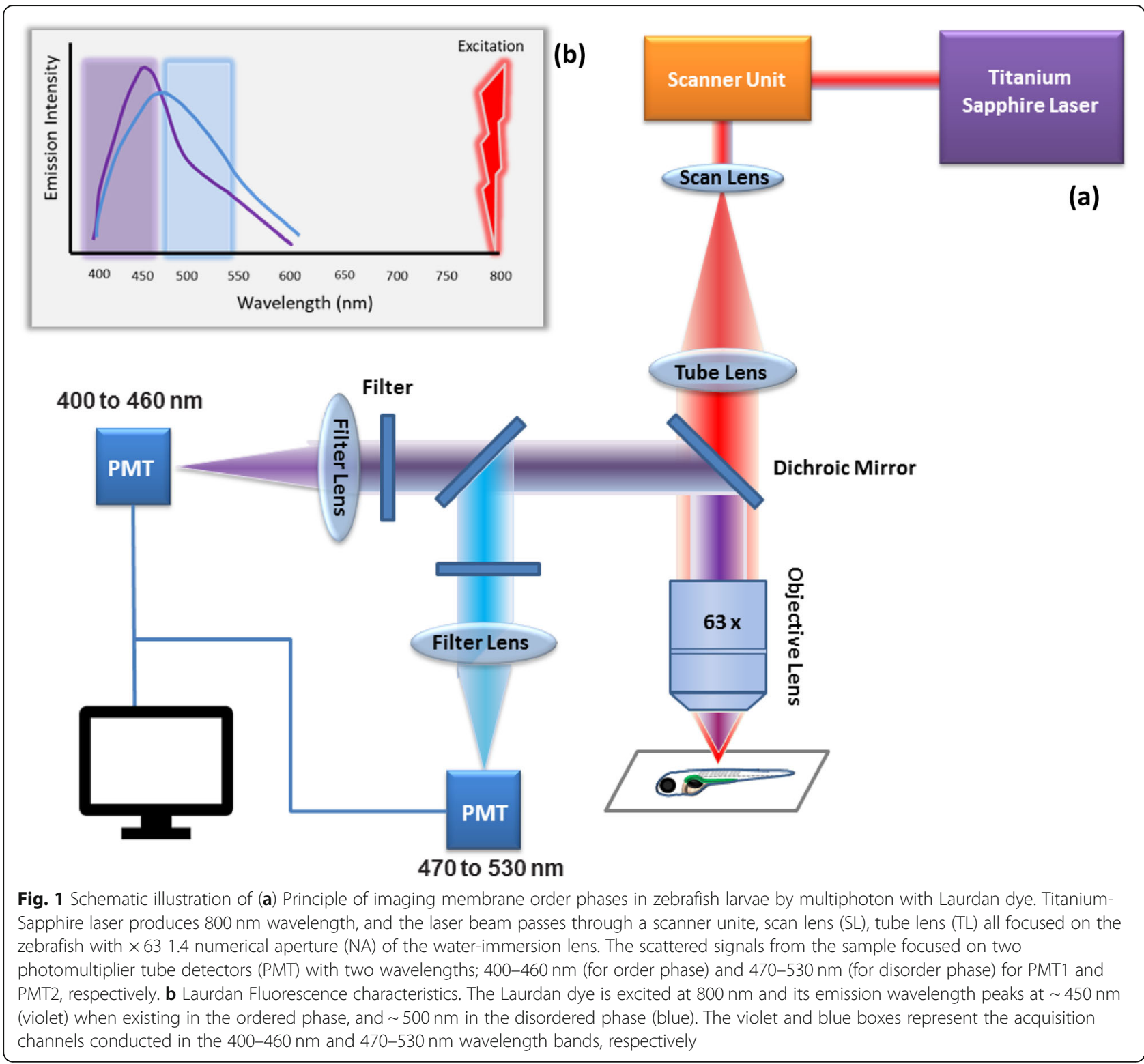

noninvasive imaging utilized in zebrafish with a precise penetration, in the millimeter range, and sub-micron three-dimensional resolution (Fig. 3).

In this technique, complex in vivo developmental processes in zebrafish embryos were successfully detected without any pretreatment within less than 1-mm-thick. Even with high illumination and long-term observations, no visible damage was detected, and no adverse effect was found on embryos until the larval stage. The threedimensional resolution enabled the researchers to acquire images of cellular processes occurring inside embryos and larvae. This effective technique provided a glance at the dynamics of cytological construction during embryogenesis, which added valuable findings to the research of developmental biology [24, 25]. For example, cell behavior during zebrafish embryo cleavage stages was successfully reconstructed in a three-dimensional (3D) imaging by combining SHG with THG in imaging zebrafish embryos without any labeling [26] (Fig. 4).

Second Harmonic Generation (SHG) was employed to study the organization of collagen during the fin wound healing in zebrafish. The outcome of this work proposed the importance of collagen fibers during fin re-growth [27]. In a similar study, collagen reorganization during development and after wound healing was investigated in zebrafish larvae by Two-Photon, SHG imaging of fluorescently labeled transgenic macrophages. This technique allowed a non-invasive assessment of collagen fibers during development, wound healing, macrophage 

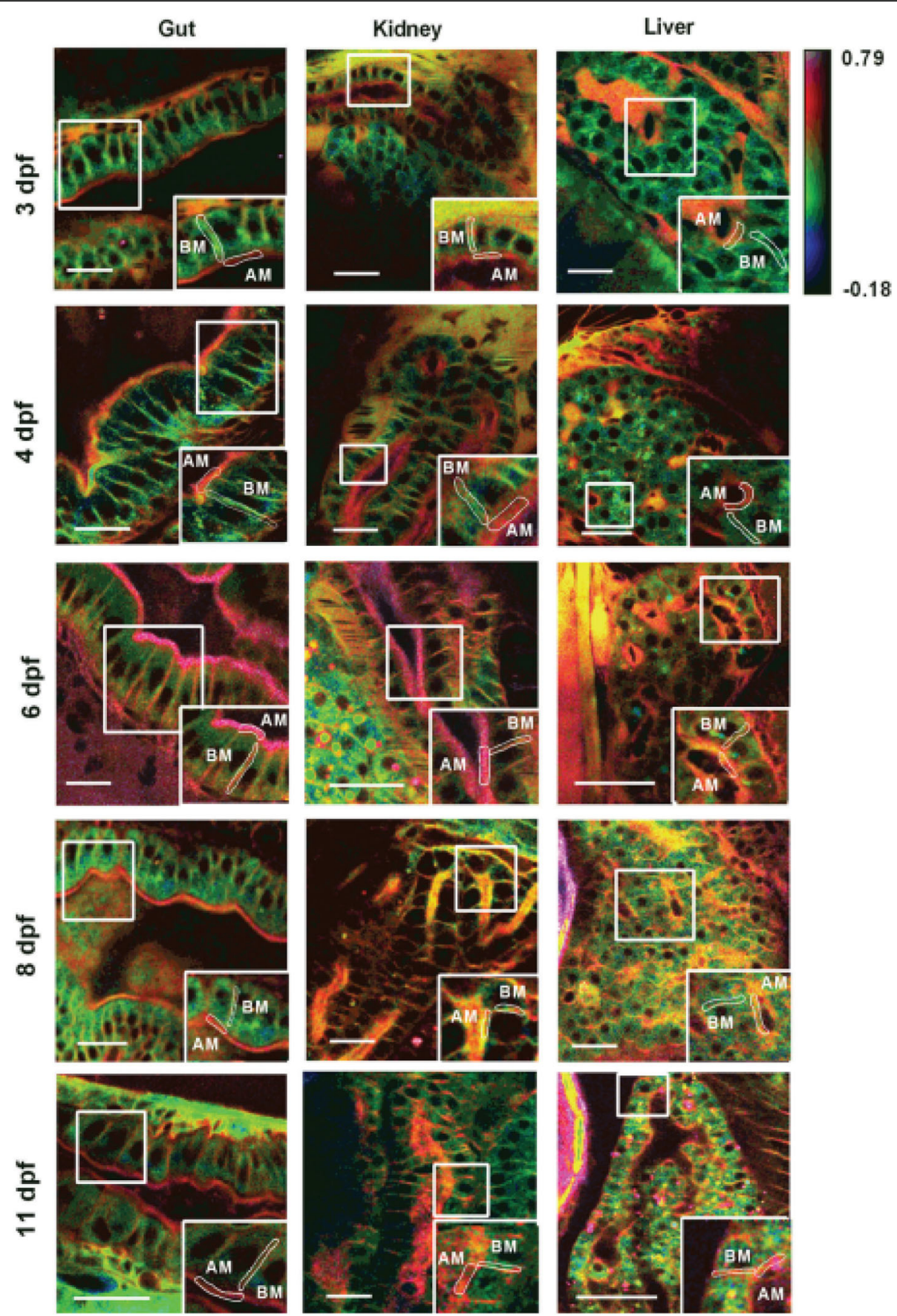

Fig. 2 Acquired images for zebrafish tissues (gut, kidney, and liver) during different developmental stages, from 3 dpf to 11 dpf by using a TwoPhoton microscope in conjugation with Laurdan dye. Scale bar $=20 \mu \mathrm{m}$. Adapted with permission from ref. [18]. Copyright $2016 \mathrm{John}$ Wiley and Sons Periodicals. *days post-fertilization

response, and potential interactions between macrophages and collagen fibers [28].

The transparency, genetic liability, and availability of fluorescently tagged immune cells of zebrafish with using the SHG imaging provided new perceptions to tissue regeneration in wound healing in a live animal.

\section{Drawbacks of Second Harmonic Generation}

Despite the effectiveness of SHG microscopy in imaging biological tissue, it still suffers from some limitations. One of these limitations is the restricted penetration depths $(100-300 \mu \mathrm{m}$ with laser excitation in the $800-1000 \mathrm{~nm}$ range). Consequently, this might make SHG microscopy inappropriate for some biological applications, mainly 


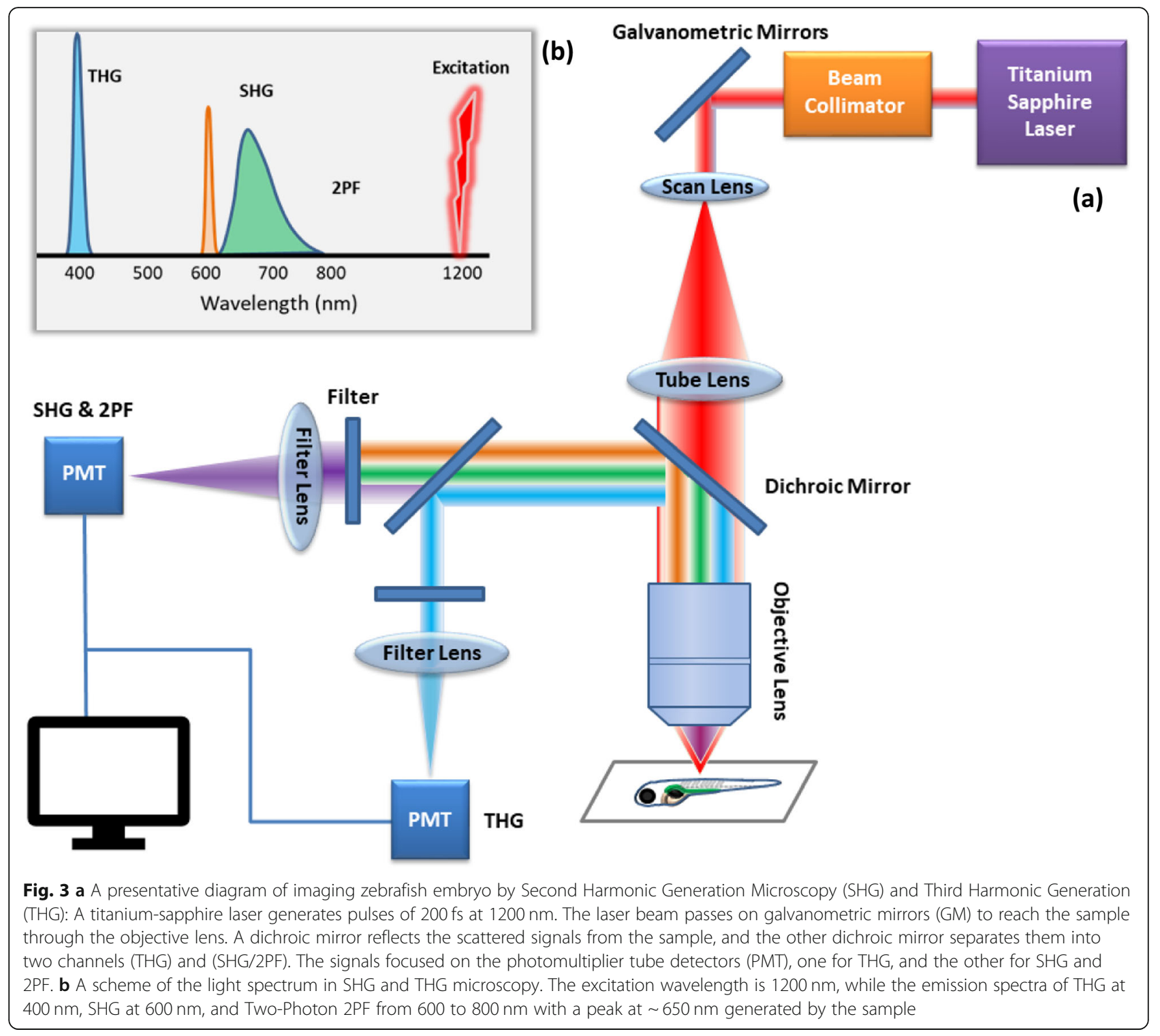

when the region of interest is deeply located within the tissue or organ; thus, it is unreachable by SHG. The biggest issue in SHG microscopy is that it can image only a few structural proteins or harmonophores such as collagen types I \& III, actomyosin complexes, cholesterol crystals (ChC), centrosomes and mitotic spindles. Unfortunately, to date, scientists could not find a method that can discriminate between fibrillar collagen types, which could enhance wound repair and regeneration biology [29]. However, these limitations might be controlled by finding suitable imaging solutions.

\section{Zebrafish by Light-Sheet Microscopy}

By exploiting the optical features of zebrafish, LightSheet Microscopy (LSM) became a preferred technique in imaging embryonic development. LSM owns various strengths such as deep optical sectioning, high frame rates, faint excitation intensities, minimal phototoxicity, moderate mounting techniques, rapid imaging with an efficient signal to noise ratio, and imaging specimens from different angles for a prolonged time [30, 31] (Fig. 5). In 2008, a digital scanned laser Light-Sheet Fluorescence Microscopy was established to report nuclear movement and localization of wild type and mutant zebrafish embryos. They were able to measure the embryonic body axis based on morphodynamic symmetry. They also created a germ layer model that demonstrated that the mesendoderm development was formed around $33 \%$ of the embryonic cells during a given phase of cell division [32]. Later, the zebrafish brain/inner ear region was successfully imaged by using improved Thin-Sheet Laser Imaging Microscope 

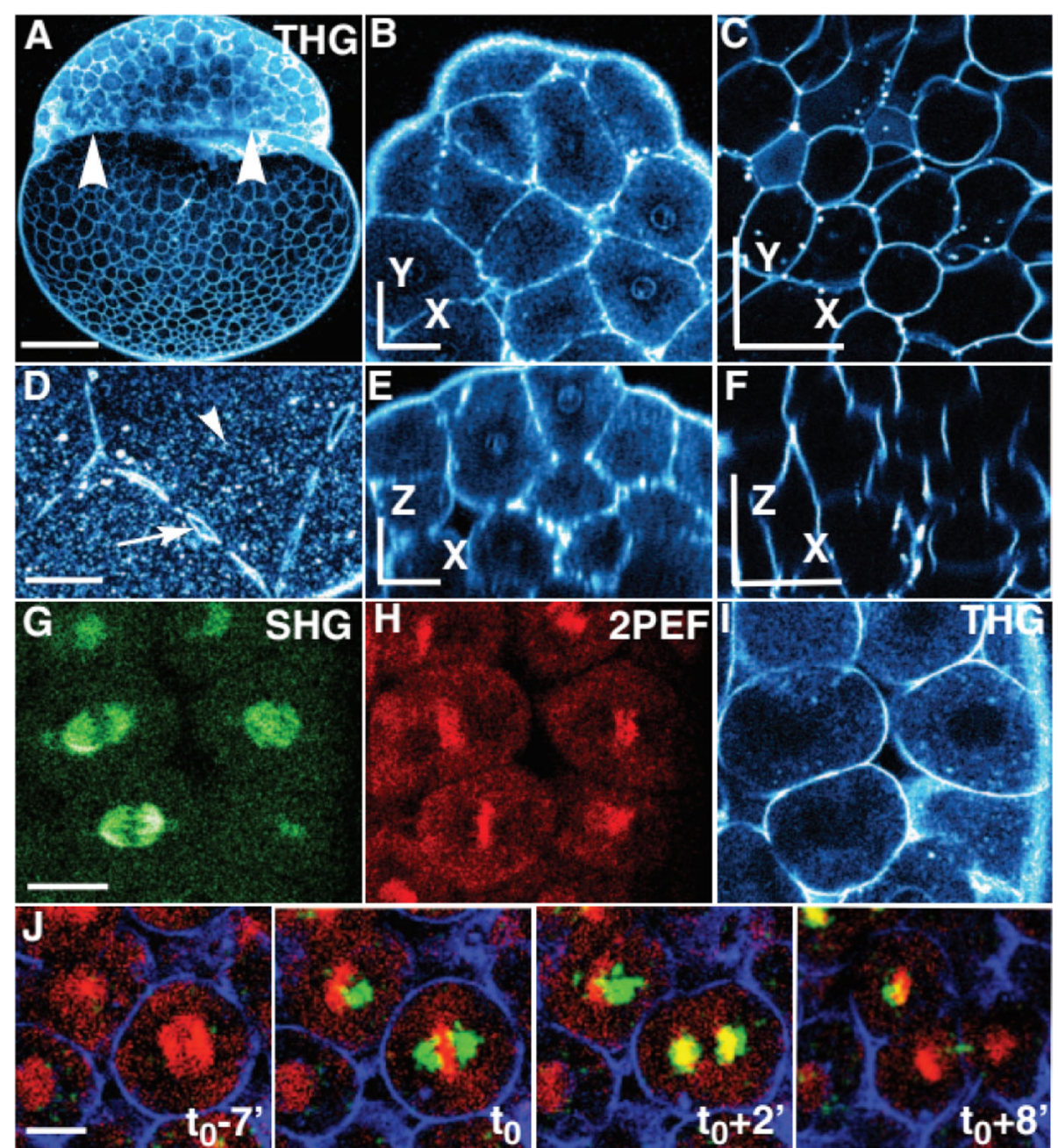

Fig. 4 Presentative images of successful in toto imaging by using a combination of THG and SHG in addition to 2PEF for imaging unlabeled zebrafish embryo during the cleavage period. Adapted with permission from ref. [25]. Copyright 2010; The American Association for the Advancement of Science (AAAS) periodicals

(TSLIM) at a comparable resolution of wide-field fluorescence microscopy succeeded in delivering an even section of illumination and decreasing penetration artifacts that the Light-Sheet Microscopy suffered from [33].

Genetically encoded calcium indicator GCaMP5G was applied by Light-Sheet Microscopy to study the in vivo imaging of more than $80 \%$ of neurons in zebrafish larval brains. In a study, two populations of neurons with correlated activity patterns were successfully identified [33]. Also, Light Sheet Fluorescence Microscopy (LSFM) was efficient in studying eye morphogenesis in zebrafish emphasizes that LSFM could be better than conventional confocal imaging for this purpose [30] (Figs. 5b, 6).

LSFM requires taking a large $z$ stack and a large field of view to display the main morphogenetic relocations followed the changeover from optic vesicle to the optical cup stage [34]. Wild type and mutant zebrafish were compared in vivo by Light-Sheet Microscopy to explore the activity of inhibitory neural networks during GABAergic signaling changing. Light-Sheet Microscopy succeeded in imaging the neural activity in two colors at 23 frames per second for over $10 \mathrm{~min}$, which granted an opportunity to record the infrequent seizure crisis in mutant type, concluded that zebrafish might be used to mimic epilepsy in human [35]. Hence zebrafish became a recognized model in studying vascular development and disease in vivo [36].

Due to limitations in the optical range and scanning speed in confocal or Two-Photon Microscopy, it was challenging to image the whole zebrafish embryonic brains. Light-Sheet Fluorescence Microscopy (LSFM) was an efficient approach in imaging the entire head of live transgenic zebrafish embryos. By creating an inclusive $3 \mathrm{D}$ maps, researchers were able to image cranial neurons and blood vessels during zebrafish embryogenesis by LSFM. Blood cells circulating through the entire 


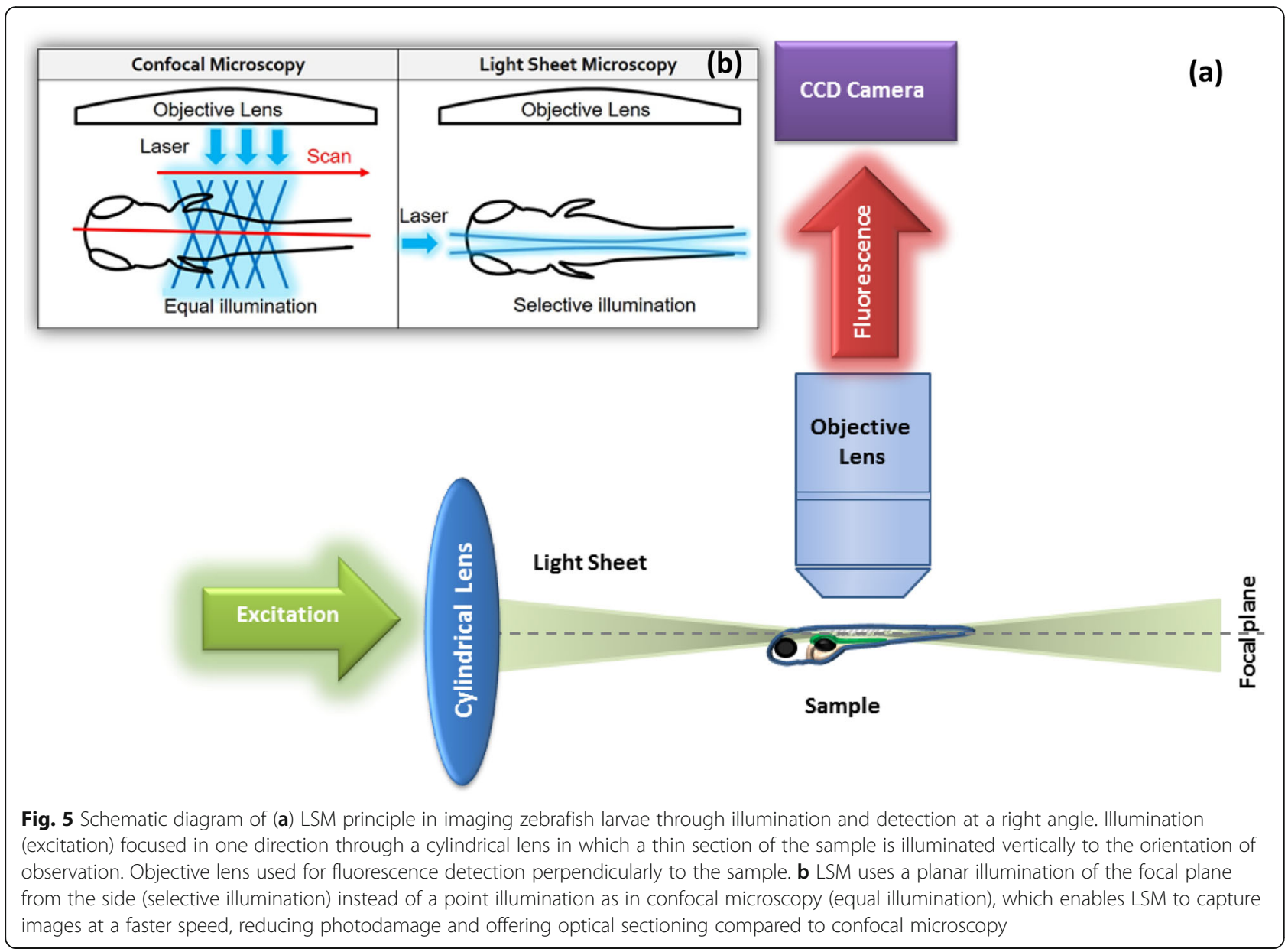

head, vagal, and cardiac vasculature at high resolution in a 3D were visualized, this came up with establishing a complete $4 \mathrm{D}$ atlas of embryogenesis and neural activity in zebrafish [37].

\section{Drawbacks of Light-Sheet Microscopy}

Although LSFM is the only technique allowing volumetric imaging without exposing the sample to light outside the focal plane, LSFM frequently needs modifications in the experimental design and has illumination issues [30]. When high-speed acquisition needs to be achieved during LSFM imaging, high peak power is required for the line-by-line illumination applied to produce a scanned light sheet. High peak power can impose the intrinsic Reactive Oxygen Species (ROS) scavenging mechanisms of living organisms, which induce photodamage in the

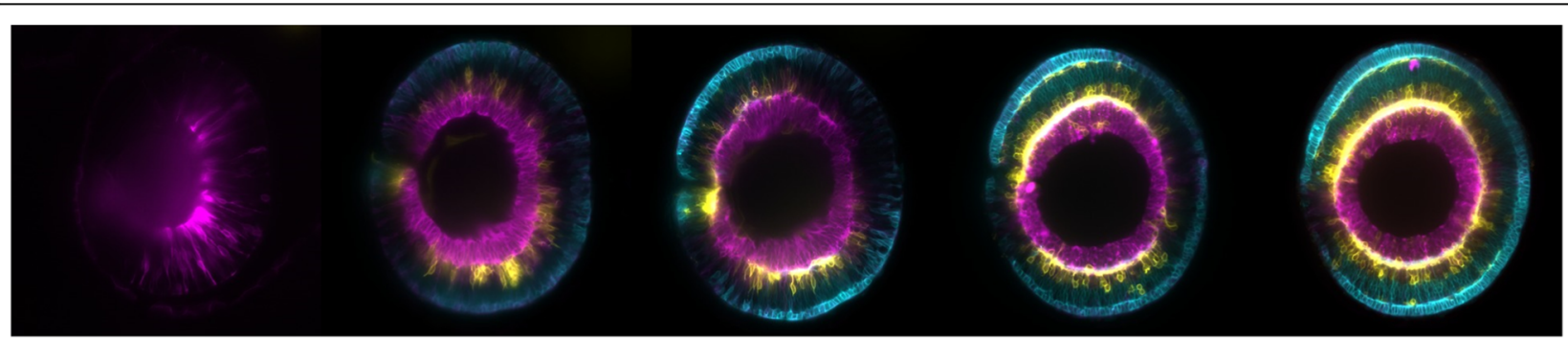

Fig. 6 Different developmental stages of the retina of zebrafish embryo acquired by Light Sheet Microscopy (LMS) from $1.5 \mathrm{dpf}$ to $3.5 \mathrm{dpf*}$. The retinal ganglion cells are shown in (magenta), the amacrine and horizontal cells are shown in (yellow), and the photoreceptors and bipolar cells are shown in (cyan). The image was created on 30 November 2015 by IchaJaroslav in the Norden lab at the Max Planck Institute of Molecular Cell Biology and Genetics (MPI-CBG) in Dresden, Germany, this file is licensed under the Creative Commons Attribution-Share Alike 4.0 International license. * days post-fertilization 
biological sample. Light-Sheet Microscopy needs a large amount of memory storage, which requires users to have impressive data storage pipelines. But this issue can be resolved by establishing a pipeline that doubles up the acquisition speed and reduces storage requirements [38]. Extra optics are required to produce the light sheet that may introduce steric constraints to the imaging system and sample mounting, which can be resolved by inducing modifications in the illumination architecture [39].

The principle, advantages, disadvantages, and the applications of the Two-Photon, Second Harmonic Generation, and Light-Sheet Microscopy are tabulated in (Table 1).

\section{Conclusion}

Despite arguments and discrepancies about the visibility of using zebrafish as a research model, different zebrafish studies have been performed without changing its viability or behavior. Therefore, it is proven that zebrafish is a promising model in the microscopy field with a variety of applications due to its robust nature, its optical amenability, and genetic traceability.

Two-Photon Microscopy is a promising approach in studying different topics in live zebrafish. Photobleaching within the focal volume is the main weak point of Two-Photon Microscopy when a proper laser intensity is used; the photodamage to the zebrafish organs during image acquisition is nearly absent.

Two-Photon also showed a virtuous capability in zebrafish embryo imaging; hence, it is considered a powerful tool for addressing current issues in systems biology and high-content experimental investigation of embryonic development.

Table 1 Summary of three microscopy techniques used in zebrafish studies

\begin{tabular}{|c|c|c|c|c|c|}
\hline Method & Principle & Advantages & Disadvantages & Applications on zebrafish & References \\
\hline $\begin{array}{l}\text { Two- } \\
\text { Photon } \\
\text { Microscopy }\end{array}$ & $\begin{array}{l}\text { - Based on nonlinear optical } \\
\text { processes. } \\
\text { - Image fluorescent dyes or } \\
\text { endogenous molecules. } \\
\text { - Near-infrared light is used } \\
\text { instead of visible. } \\
\text { - Two-photon excited fluores- } \\
\text { cence is based on the sim- } \\
\text { ultaneous absorption of } \\
\text { two lower-energy photons. }\end{array}$ & $\begin{array}{l}\text { - Suitable for imaging op- } \\
\text { tically thick specimens. } \\
\text { - Less scattering and } \\
\text { absorption in biological } \\
\text { tissue, permitting for } \\
\text { deeper penetration. } \\
\text { - No pinhole aperture and } \\
\text { minimizes signal loss. } \\
\text { - Photobleaching of } \\
\text { fluorescent molecules } \\
\text { outside the focus is } \\
\text { almost abolished. } \\
\text { - High resolution in } \\
\text { imaging intact biological } \\
\text { samples without spatial } \\
\text { filtering. }\end{array}$ & $\begin{array}{l}\text { - Photobleaching within the } \\
\text { focal volume, with laser power } \\
\text { levels typically used in bio- } \\
\text { logical imaging. } \\
\text { - Induce considerable } \\
\text { photodamage at the focal } \\
\text { volume where photochemical } \\
\text { interactions occur. }\end{array}$ & $\begin{array}{l}\text { 1. Study morphogenetic } \\
\text { movements during early } \\
\text { zebrafish embryonic } \\
\text { development } \\
\text { 2. Measure membrane order } \\
\text { in tissues of zebrafish larvae. } \\
\text { 3. Neural Population Activity } \\
\text { in Zebrafish } \\
\text { 4. Studying membrane order } \\
\text { polarity proteins in the gut, } \\
\text { kidney, and liver during } \\
\text { vertebrate organogenesis. }\end{array}$ & $\begin{array}{l}\text { 1. Carvalho } \\
\text { \& } \\
\text { Heisenberg } \\
\text { 2009 [1] } \\
\text { 2. Owen } \\
\text { et al. } 2010 \\
\text { [12] } \\
\text { 3. } \\
\text { Renninger } \\
\text { \& Orger } \\
\text { 2013 [17] } \\
\text { 4. Abu- } \\
\text { Siniyeh } \\
\text { et al. } 2016 \\
\text { [18] }\end{array}$ \\
\hline $\begin{array}{l}\text { Second } \\
\text { Harmonic } \\
\text { Generation }\end{array}$ & $\begin{array}{l}\text { - Used to image non- } \\
\text { centrosymmetric structures } \\
\text { such as collagen fibers and } \\
\text { - A nonlinear optical process } \\
\text { where two photons are } \\
\text { converted to a single } \\
\text { photon without losing any } \\
\text { energy. }\end{array}$ & $\begin{array}{l}\text { - Visualizes the tissue } \\
\text { structure directly } \\
\text { because the contrast is } \\
\text { produced from } \\
\text { endogenous species. } \\
\text { - Significantly reduced } \\
\text { photobleaching and } \\
\text { phototoxicity compared } \\
\text { to fluorescence methods. } \\
\text { - It can reach high- } \\
\text { resolution imaging to } \\
\text { several hundred microns } \\
\text { depths. }\end{array}$ & $\begin{array}{l}\text { - Limited penetration depths } \\
100-300 \mu \mathrm{m} \text { with laser } \\
\text { excitation in the } 800-1000 \mathrm{~nm} \\
\text { range to increase image } \\
\text { resolution. } \\
\text { - Micrometer depths are often } \\
\text { inadequate for in vivo } \\
\text { applications. }\end{array}$ & $\begin{array}{l}\text { 1. Collagen organization in } \\
\text { zebrafish during wound } \\
\text { healing. } \\
\text { 2. Gene expression } \\
\text { observation in zebrafish } \\
\text { embryo nerve systems. }\end{array}$ & $\begin{array}{l}\text { 1. LeBert } \\
\text { et al. } 2015 \\
\text { [27] } \\
\text { 1. LeBert } \\
\text { et al. } 2016 \\
\text { [28] } \\
\text { 2. Hsieh } \\
\text { et al. } 2008 \\
\text { [40] }\end{array}$ \\
\hline $\begin{array}{l}\text { Light- } \\
\text { Sheet } \\
\text { Microscopy }\end{array}$ & $\begin{array}{l}\text { - The defining feature of LSM } \\
\text { is the planar illumination of } \\
\text { the focal plane from the } \\
\text { side. } \\
\text { - Only a thin section of the } \\
\text { sample is illuminated at any } \\
\text { given time. }\end{array}$ & $\begin{array}{l}\text { - Rapid imaging with high } \\
\text { frame rates } \\
\text { - High signal-to-noise } \\
\text { ratios. } \\
\text { - Minimum rates of photo- } \\
\text { bleaching and toxicity. } \\
\text { - Three-dimensional im- } \\
\text { aging of live samples. } \\
\text { - Minimized } \\
\text { photodamage. } \\
\text { - Deep optical sectioning. } \\
\text { - Faint excitation } \\
\text { intensities. } \\
\text { - Moderate mounting } \\
\text { techniques. }\end{array}$ & $\begin{array}{l}\text { - Extra optics are required to } \\
\text { produce the light sheet. } \\
\text { - Adding the extra lens } \\
\text { introduces steric constraints to } \\
\text { the imaging system and } \\
\text { sample mounting. }\end{array}$ & $\begin{array}{l}\text { 1. Image zebrafish eye } \\
\text { development } \\
\text { 2. Imaging a seizure model } \\
\text { in zebrafish } \\
\text { 3. Zebrafish vascular } \\
\text { development } \\
\text { 4. Brain functional imaging } \\
\text { 5. } 3 \text { D imaging of cranial } \\
\text { neurons and vasculature } \\
\text { during zebrafish } \\
\text { embryogenesis. }\end{array}$ & $\begin{array}{l}\text { 1. Icha et al. } \\
\text { 2016 [34] } \\
\text { 2. Kner } \\
\text { et al. } 2018 \\
\text { [35] } \\
\text { 3. Kugler } \\
\text { et al. } 2018 \\
\text { [36] } \\
\text { 4. Misha } \\
\text { et al. } 2013 \\
\text { [41] } \\
\text { 5. Ok Kyu } \\
\text { Park et al. } \\
\text { 2015 [42] }\end{array}$ \\
\hline
\end{tabular}


The Second Harmonic Generation (SHG) has many advantages. It is suitable to image intact and living tissues without labeling. Besides, its near-infrared excitation is nonlinear, which enables optical sectioning with minimal autofluorescence background and minimal photochemical damage of biological samples. SHG involves no absorption because it is a non-resonant process. The constraint of weak signal intensity of harmonic generation has been fixed by increasing the repetition rate of the excitation light.

SHG imaging is a promising tool for studying structural proteins in-vivo, mainly collagen and the muscle sarcomeres of zebrafish during its early development. It became more efficient in zebrafish when it used with genetically encoded fluorescent tags. There is a potential advantage of combing SHG with THG as this could identify gene expression levels in the embryonic nervous system in zebrafish in addition to recording and imaging the performance of the cell during the developmental stages of the zebrafish embryo (Fig. 4).

Light-Sheet Microscopy (LSFM) enables rapid imaging, high signal-to-noise ratios, and minimum rates of photobleaching and toxicity, three-dimensional imaging of live samples. These capabilities allowed scientists to quantify cellular dynamics in entire embryos throughout their development. LSFM owns an advanced ability, such as $4 \mathrm{D}$ in vivo imaging to reveal volumetric cellular structures in tissues during development. The LSFM has been combined with Structured Illumination (SI) to eliminate scattered and out-of-focus light. This powerful combination enhanced the resolution and contrast in the vertical and axial directions during imaging neural activity at the zebrafish larval stage.

In summary, each of these three advanced microscopy techniques owns its advantages and disadvantages when it was implemented in vivo studies. In the future, we recommend for further improvement by combining two different modalities for addressing more effective visualization. A successful model was an integration of one and TwoPhoton scanned oblique plane illumination microscopy that provided light-sheet scanning based rapid volumetric imaging ability at subcellular resolution. High-resolution nonlinear optical microscopy with zebrafish as an animal model can revoke many challenges that limit detecting changes at the tissue structure during pathoetiologies.

\footnotetext{
Abbreviations

ChC: Cholesterol Crystals; dpf: days post fertilization; FCS: Fluorescence Correlation Spectroscopy; FLIM: Fluorescence Lifetime Imaging; FRET: Förster Resonant Energy Transfer; GCaMP5G: Genetically encoded calcium indicator; GCaMP6: Green fluorescent calcium biosensor; GFP: Green Fluorescent Protein; LSFM: Light Sheet Fluorescence Microscopy; LSM: Light-Sheet Microscopy; MPM: Multi-Photon Microscopy; OPT: Optical Projection Tomography; Pd2+: Palladium 2+; ROS: Reactive Oxygen Species; SHG: Second Harmonic Generation; SI: Structured Illumination; TPM: TwoPhoton Microscopy; TSLIM: Thin-Sheet Laser Imaging Microscope
}

\section{Acknowledgments}

The authors thank Dr. Joanna Kwiatek from the Department of Food Science and the Rutgers Center for Lipid Research, New Jersey Institute for Food, Nutrition, and Health, Rutgers University, New Brunswick, New Jersey 08901, for giving positive feedback on this review.

\section{Authors' contributions}

Both authors contributed equally to this manuscript. The author(s) read and approved the final manuscript.

\section{Funding}

This review received no external funding.

\section{Availability of data and materials}

The dataset supporting the conclusions of this article is included within the article and its additional file.

\section{Competing interests}

The authors declare that they have no competing interests.

\section{Author details}

${ }^{1}$ Clinical Laboratory Sciences Department, College of Applied Medical Science, Taif University, Taif, Kingdom of Saudi Arabia. ${ }^{2}$ Department of Biomedical Engineering, School of Applied Medical Sciences, German Jordanian University, Amman, Jordan.

Received: 13 January 2020 Accepted: 6 April 2020

Published online: 22 April 2020

\section{References}

1. Carvalho L, Heisenberg C-P. Imaging zebrafish embryos by two-photon excitation time-lapse microscopy; 2009. p. 273-87.

2. Shi X, Foo YH, Korzh V, Ahmed S, Wohland T. Applications of fluorescence correlation spectroscopy in living zebrafish embryos. In: Live imaging in zebrafish; 2010. p. 69-103.

3. Logan SL, Dudley C, Baker RP, Taormina MJ, Hay EA, Parthasarathy R. Automated high-throughput light-sheet fluorescence microscopy of larval zebrafish. Tanguay RL, editor. PLoS One. 2018;13(11):e0198705.

4. Vascotto SG, Beckham Y, Kelly GM. The zebrafish's swim to fame as an experimental model in biology. Biochem Cell Biol Biochim Biol Cell. 1997; 75(5):479-85.

5. Grunwald DJ, Eisen JS. Headwaters of the zebrafish -- emergence of a new model vertebrate. Nat Rev Genet. 2002;3(9):717-24.

6. Amsterdam A, Hopkins N. Mutagenesis strategies in zebrafish for identifying genes involved in development and disease. Trends Genet. 2006;22(9):473-8

7. Laughlin ST, Baskin JM, Amacher SLBC. In vivo imaging of membraneassociated glycans in developing zebrafish. Science (80- ). 2008;320(5876): $664-7$

8. van Ham TJ, Mapes J, Kokel D, RTP. Live imaging of apoptotic cells in zebrafish. FASEB J. 2010;24(11):4336-42.

9. Andrews N, Ramel MC, Kumar S, Alexandrov Y, Kelly DJ, Warren SC, et al. Visualising apoptosis in live zebrafish using fluorescence lifetime imaging with optical projection tomography to map FRET biosensor activity in space and time. J Biophotonics. 2016;9(4):414-24.

10. Zhao M, Wan X, Li Y, Zhou W, Peng L. Multiplexed 3D FRET imaging in deep tissue of live embryos. Sci Rep. 2015:5:13991.

11. Li L, Guan R, Guo M, Ning P, Shao R, Meng X. A FRET based two-photon fluorescent probe for ratiometric detection of $\mathrm{Pd} 2+$ in living cells and in vivo. Sensors Actuators B Chem. 2018;254:949-55.

12. Owen DM, Magenau A, Majumdar A, Gaus K. Imaging membrane lipid order in whole, living vertebrate organisms. Biophys J. 2010;99(1):L7-9 [cited 2010 Jul 7].

13. Hölttä-Vuori M, Uronen R-L, Repakova J, Salonen E, Vattulainen I, Panula P, et al. BODIPY-cholesterol: a new tool to visualize sterol trafficking in living cells and organisms. Traffic. 2008;9(11):1839-49.

14. Stoletov K, Fang L, Choi S-H, Hartvigsen K, Hansen LF, Hall C, et al. Vascular lipid accumulation, lipoprotein oxidation, and macrophage lipid uptake in hypercholesterolemic zebrafish. Circ Res. 2009;104(8):952-60. 
15. Kwiatek JM, Owen DM, Abu-Siniyeh A, Yan P, Loew LM, Gaus K. Characterization of a new series of fluorescent probes for imaging membrane order. PLoS One. 2013;8(2):e52960.

16. Hölttä-Vuori M, Salo VTV, Nyberg L, Brackmann C, Enejder A, Panula P, et al. Zebrafish: gaining popularity in lipid research. Biochem J. 2010;429(2): 235-42 [cited 2010 Sep 21].

17. Renninger SL, Orger MB. Two-photon imaging of neural population activity in zebrafish. Methods. 2013;62(3):255-67.

18. Abu-Siniyeh A, Owen DM, Benzing C, Rinkwitz S, Becker TS, Majumdar A, et al. The aPKC/Par3/Par6 polarity complex and membrane order are functionally interdependent in epithelia during vertebrate organogenesis. Traffic. 2016;17(1):66.

19. Bixler JN, Hokr BH, Denton ML, Noojin GD, Shingledecker AD, Beier HT, et al. Assessment of tissue heating under tunable near-infrared radiation. J Biomed Opt. 2014;19(7):070501. 1.

20. Ji N, Magee JC, Betzig E. High-speed, low-photodamage nonlinear imaging using passive pulse splitters. Nat Methods. 2008;5(2):197-202.

21. Hopt A, Neher E. Highly nonlinear photodamage in two-photon fluorescence microscopy. Biophys J. 2001;80(4):2029-36.

22. Débarre D, Olivier N, Supatto W, Beaurepaire E. Mitigating phototoxicity during multiphoton microscopy of live drosophila embryos in the 1.0-1.2 $\mu \mathrm{m}$ wavelength range. Coles JA, editor. PLoS One. 2014;9(8):e104250.

23. Icha J, Weber M, Waters JC, Norden C. Phototoxicity in live fluorescence microscopy, and how to avoid it. BioEssays. 2017;39(8):1700003.

24. Sun C-K, Chu S-W, Chen S-Y, Tsai T-H, Liu T-M, Lin C-Y, et al. Higher harmonic generation microscopy for developmental biology. J Struct Biol. 2004;147(1):19-30.

25. Pantazis P, Maloney J, Wu D, Fraser SE. Second harmonic generating (SHG) nanoprobes for in vivo imaging. Proc Natl Acad Sci. 2010;107(33):14535-40.

26. Olivier N, Luengo-Oroz MA, Duloquin L, Faure E, Savy T, Veilleux I, et al. Cell lineage reconstruction of early zebrafish embryos using label-free nonlinear microscopy. Science (80- ). 2010;329(5994):967-71.

27. LeBert DC, Squirrell JM, Rindy J, Broadbridge E, Lui Y, Zakrzewska A, et al. Matrix metalloproteinase 9 modulates collagen matrices and wound repair. Development. 2015;142(12):2136-46.

28. LeBert DC, Squirrell JM, Huttenlocher A, Eliceiri KW. Second harmonic generation microscopy in zebrafish; 2016. p. 55-68.

29. Mostaço-Guidolin L, Rosin N, Hackett T-L. Imaging collagen in scar tissue: developments in second harmonic generation microscopy for biomedical applications. Int J Mol Sci. 2017;18(8):1772.

30. Reynaud EG, Kržič U, Greger K, Stelzer EHK. Light sheet-based fluorescence microscopy: more dimensions, more photons, and less photodamage. HFSP J. 2008;2(5):266-75.

31. Hanrahan O. Light-sheet microscopy advances biological study. BioPhotonics. 2014. BioPhotonics. Web.

32. Keller PJ, Schmidt AD, Wittbrodt J, EHKS. Reconstruction of zebrafish early embryonic development by scanned light sheet microscopy. Science (80- ). 2008;322(5904):1065-9.

33. Santi PA, Johnson SB, Hillenbrand M, Grandpre PZ, Glass TJ, Leger JR. Thinsheet laser imaging microscopy for optical sectioning of thick tissues. Biotechniques. 2009;46(4):287-94.

34. Icha J, Schmied C, Sidhaye J, Tomancak P, Preibisch S, NC and CN. Using light sheet fluorescence microscopy to image zebrafish eye development. J Vis Exp. 2016;110:53966.

35. Kner P, Liu Y, Dale S, Ball R, VanLeuven AJ, Baraban S, et al. Imaging a seizure model in zebrafish with structured illumination light sheet microscopy. In: Brown TG, Cogswell CJ, Wilson T, editors. Three-dimensional and multidimensional microscopy: image acquisition and processing XXV. SPIE; 2018. p. 38.

36. Kugler $\mathrm{E}$, Chico T, Armitage P. Image analysis in light sheet fluorescence microscopy images of transgenic zebrafish vascular development. In: Nixon M, Mahmoodi S, Zwiggelaar R, editors. Medical image understanding and analysis. Cham: Springer International Publishing; 2018. p. 343-53.

37. Chen B-C, Legant WR, Wang K, Shao L, Milkie DE, Davidson MW, et al. Lattice light-sheet microscopy: Imaging molecules to embryos at high spatiotemporal resolution. Science (80- ). 2014;346(6208):1257998.

38. de Medeiros G, Norlin N, Gunther S, Albert M, Panavaite L, Fiuza U-M, et al. Confocal multiview light-sheet microscopy. Nat Commun. 2015;6(1):8881.

39. Kumar M, Kishore S, Nasenbeny J, McLean DL, Kozorovitskiy Y. Integrated one- and two-photon scanned oblique plane illumination (SOPi) microscopy for rapid volumetric imaging. Opt Express. 2018;26(10):13027.
40. Hsieh C-S, Ko C-Y, Chen S-Y, et al. In vivo long-term continuous observation of gene expression in zebrafish embryo nerve systems by using harmonic generation microscopy and morphant technology. J Biomed Opt. 2008; 13(6):064041.

41. Ahrens MB, Orger MB, Robson DN, JML\& PJK. Whole-brain functional imaging at cellular resolution using light-sheet microscopy. Nat Methods. 2013;10:413-20.

42. Ok Kyu Park, Jina Kwak, Yoo Jung Jung, Young Ho Kim, Hyun-Seok Hong, Byung Joon Hwang, Seung-Hae Kwon and YK. 3D Light-Sheet Fluorescence Microscopy of Cranial Neurons and Vasculature during Zebrafish Embryogenesis. Mol Cells. 2015;38(11):975-81.

\section{Publisher's Note}

Springer Nature remains neutral with regard to jurisdictional claims in published maps and institutional affiliations.
Ready to submit your research? Choose BMC and benefit from:

- fast, convenient online submission

- thorough peer review by experienced researchers in your field

- rapid publication on acceptance

- support for research data, including large and complex data types

- gold Open Access which fosters wider collaboration and increased citations

- maximum visibility for your research: over $100 \mathrm{M}$ website views per year

At BMC, research is always in progress.

Learn more biomedcentral.com/submissions 